\title{
COMPLETE FRACTURES OF THE FEMUR IN PAGET'S DISEASE OF BONE
}

\author{
JOHN DOVE \\ From The Royal Orthopaedic Hospital, Birmingham
}

\begin{abstract}
Complete fractures through bone affected by Paget's disease may not deserve their innocent reputation. This retrospective study of 182 such femoral fractures, the largest reported series to date, was carried out to discover the behaviour of these fractures in the absence of specific therapy for the Paget's disease. Most previous series have concluded that healing is uneventful but the findings in these patients from the West Midlands do not bear this out. After exclusion of the early deaths, the overall incidence of non-union was $\mathbf{4 0}$ per cent, the main problems being posed by the subtrochanteric fractures and those of the upper shaft. Although callus may be abundant, it may itself be involved in the disease process and is not a reliable sign of union. Based on these observations, suggestions for management in the different regions of the femur are made.
\end{abstract}

It is now just over 100 years since Sir James Paget (1877) first described the disease of bone which bears his name, but in the last decade widespread interest has been reawakened dating from the introduction of calcitonin, the first specific therapy (Bijvoet and Jansen 1967).

Fractures complicating Paget's disease have received much less attention than the treatment of the underlying disease. The first report was by Woytek (1932) but he was concerned with the incidence and did not comment on the outcome of the fractures. Although there has been a carefully controlled study of incomplete or fissure fractures (Redden, Hosking and Vennart 1977), complete fractures have not been so well studied.

There is a widely held view that fracture healing in Paget's disease is not a problem, although the rate of healing has been variously reported (Table I). Fractures of the femur have been included in previous reports of fractures in Paget's disease. Table II shows details of the published data but includes only series with 20 or more fractures of the femur since many reports dealt with only one or two fractures which healed uneventfully and thus were mainly responsible for the innocent reputation of this injury (Murphy 1934; Rogers and Ulin 1936; Traver 1936; Tavernier and Lasserre 1937; Brailsford 1938; Dickson, Camp and Ghormley 1945; Newman 1946; de Sèze, Lasserre and Mazabraud 1956; Lasserre 1956; de Mourgues, Comtet and Fischer 1967; Marchi and Cittadini 1968; Daniluk and Witwicki 1975; Louyot et al. 1975; Berruex 1978). However, Lake (1951) reported an 18 per cent incidence of delayed union or non-union and was the first to suggest that femoral fractures in Paget's disease might constitute a problem. Grundy (1970) stated that the cumulative figures from previous series were too small to allow the effectiveness of the various treatments to be analysed, yet recommendations for treatment have continued to be made on very small numbers. Beyer and Paul (1972) recommended

Table I. Reported rate of healing of fractures in Paget's disease of bone

\begin{tabular}{|l|l|l|}
\hline \multicolumn{1}{|c|}{ Quick } & \multicolumn{1}{|c|}{ Normal } & \multicolumn{1}{c|}{ Slow } \\
\hline Devas 1977 & Ackerman et al. 1976 & Apley 1977 \\
Paterson 1974 & Adams 1978 & DePalma 1970 \\
Scott 1973 & MacLeod 1974 & London 1967 \\
Simon 1973 & Rains and Ritchie 1977 & $\begin{array}{l}\text { Rockwood and } \\
\text { Green 1975 }\end{array}$ \\
Wilson 1976 & Wiles and Sweetnam 1965 & Turek 1977 \\
\hline
\end{tabular}

Table II. Reported series of fractures of the femur in Paget's disease of bone

\begin{tabular}{|l|c|c|cr|}
\hline \multicolumn{1}{|c|}{ Author } & Patients & $\begin{array}{c}\text { Femoral } \\
\text { fractures }\end{array}$ & \multicolumn{2}{c|}{ Results } \\
\hline Lake 1958 & 78 & 41 & 14 & $\mathrm{D}+\mathrm{N}$ \\
Nicholas and Killoran 1965 & 23 & 23 & & $3 \mathrm{~N}$ \\
Barry 1969 & 90 & 90 & $6 \mathrm{D}$ & $11 \mathrm{~N}$ \\
Grundy 1970 & 48 & 63 & & $16 \mathrm{~N}$ \\
Boxus 1974 & 33 & 22 & 3D & $1 \mathrm{~N}$ \\
Lemaire 1974 & 25 & 21 & 2D & $1 \mathrm{~N}$ \\
Rauis 1974 & 50 & 36 & 4D & $2 \mathrm{~N}$ \\
\hline
\end{tabular}

$\mathrm{D}=$ delayed union $\quad \mathrm{N}=$ non-union 
conservative treatment after their experience with four patients on whom they had operated and Driessen and Magerl (1976), after treating six patients, recommended rigid fixation.

Having decided to set up a prospective, controlled study into the value of calcitonin in the management of complete fractures of the femur in Paget's disease of bone, I first carried out this retrospective study. Its purpose was two-fold: to discover the behaviour of these fractures without calcitonin and to formulate recommendations for treatment based on a large number of cases.

\section{MATERIAL AND METHODS}

An examination was made of hospital records of patients with Paget's disease who had suffered a femoral fracture and who were subsequently seen in the West Midlands in the years 1973 to 1977 . The criteria for admission to the study were: a complete fracture through bone affected by Paget's disease; the absence of specific therapy for the Paget's disease; and sufficient clinical and radiological evidence to assess the outcome. All notes and radiographs were personally reviewed.

The radiological diagnosis of Paget's disease is rarely in doubt and the criteria of Murray and Jacobson (1977) were used in this study. If there was any doubt, the case was not included unless there was corroborative histological evidence from a bone biopsy. No case of $\mathrm{j}$-venile Paget's disease was included because it is rare and is likely to be a different disease (Jacobs 1974; Blanco et al. 1977).

Definitions. The femur was subdivided into the following regions: neck, trochanteric, subtrochanteric, uppermost, middle and lowermost thirds of shaft and supracondylar. The subtrochanteric region was arbitrarily defined as that portion of the shaft lying between a line drawn at right angles to the cortex through the base of the lesser trochanter and a line 2.5 centimetres distal to this. The supracondylar region was that portion of the shaft distal to a line drawn at right angles to the cortex 2.5 centimetres proximal to the adductor tubercle. The femoral shaft between these two regions was divided equally into three.

In this study the normal time to union in fractures of the normal femur was taken as follows: the neck of the femur, nine months (Barnes et al. 1976); the trochanteric region, three months; the subtrochanteric region, four months (Zickel 1976); and the shaft, three months (Hubbard 1974). Delayed union was defined as occurring either when these times were exceeded by at least three months but the fracture later united, or when the patient was lost to follow-up with the fracture still ununited after the same time even though some of these almost certainly went on to non-union. Non-union was defined as occurring either when the normal time for union had been doubled without union occurring and without further progress towards union over a three-month period, or when there was established radiological evidence of hypertrophic non-union. Cases in which the patient died before the normally expected time for union have not been included as non-unions but as "normal unions".

\section{RESULTS}

There were 182 fractures in 182 patients. There were 103 women and 79 men (a ratio of 1.3:1). The average age of the men was 67.8 years (range 53 to 98 years) and of the women 79.7 years (range 54 to 98 years). Thirty-two patients (18 per cent) died within three months of fracture. The remaining 150 patients (on whom all subsequent calculations concerning union are based) were followed up for an average of three years
Table III. Distribution of the fractures within the femur

\begin{tabular}{|l|c|c|}
\hline \multicolumn{1}{|c|}{ Site } & $\begin{array}{c}\text { Total } \\
\text { fractures }\end{array}$ & $\begin{array}{c}\text { Number of fractures } \\
\text { excluding } \\
\text { early deaths }\end{array}$ \\
\hline Neck & 31 & 21 \\
Trochanteric & 29 & 21 \\
Subtrochanteric & 49 & 46 \\
Shaft- & & \\
uppermost third & 27 & 22 \\
middle third & 35 & 29 \\
lowermost third & 9 & 9 \\
Supracondylar & 2 & 2 \\
\hline Total & 182 & 150 \\
\hline
\end{tabular}

four months (range three months to 13 years) from the date of the fracture. Table III shows the distribution of the fractures within the femur.

Table IV shows the outcome: the overall incidence of non-union was 40 per cent. Of the 60 cases of non-union, 41 (68 per cent) were of the radiologically hypertrophic type. Of the remaining 19 patients, nine (15 per cent) continued under clinical review and because of age and infirmity the non-union was

Table IV. Outcome of fractures of the femur in Paget's disease of bone

\begin{tabular}{|l|c|c|c|}
\hline & Normal union & Delayed union & Non-union \\
\hline Male & 28 & 12 & 36 \\
Female & 40 & 10 & 24 \\
\hline Total & 68 & 22 & 60 \\
& $(45$ per cent) & $(15$ per cent $)$ & $(40$ per cent $)$ \\
\hline
\end{tabular}

accepted; seven (12 per cent) had died and the remaining three (five per cent) were reviewed by the author and the radiological diagnosis of non-union as defined in this study was confirmed.

In the following paragraphs the results at each femoral level are presented.

Femoral neck fractures (21). The incidence of non-union was 75 per cent. Of those treated conservatively or by internal fixation (12 cases), 75 per cent had a painful non-union whereas of those treated by a primary femoral head replacement (nine cases), 77.8 per cent were able to walk without pain. In the latter group bone cement was used in each case and in only one was the prosthesis definitely loose. In no case did the notes make special comment of any difficulty at operation. Only one showed evidence of protrusio acetabuli at two years. Trochanteric fractures (21). The incidence of non-union was 14 per cent. Of the 15 fractures treated by internal fixation the only three cases of non-union were in those 
where a one-piece nail-plate had been used. The death rate in the conservatively treated patients was 72 per cent.

Subtrochanteric fractures (46). The incidence of nonunion was 34.8 per cent. The difference in non-union between the 37 patients treated by operation and nine treated conservatively was not significant, but 89 per cent of the latter developed a varus deformity compared with only 23 per cent of the operated group and the

Table $\mathbf{V}$. Internal fixation of subtrochanteric fractures

\begin{tabular}{|l|c|c|c|}
\hline \multicolumn{1}{|c|}{ Fixation } & Patients & $\begin{array}{c}\text { Union } \\
\text { (per cent) }\end{array}$ & $\begin{array}{c}\text { Non-union } \\
\text { (per cent) }\end{array}$ \\
\hline Intramedullary nail & 18 & 62.5 & 37.5 \\
Two-piece pin and plate & 15 & 87.0 & 13.0 \\
One-piece nail-plate & 3 & 33.3 & 66.7 \\
Zickel apparatus & 1 & 100 & 0 \\
\hline
\end{tabular}

death rate in the conservative group was three times as high (78 per cent). Table $\mathrm{V}$ compares the methods of internal fixation at this level. Non-union was more common with an intramedullary nail which was technically more difficult to insert (see below). The Zickel apparatus was used in a case with only minor deformity. Fractures of the uppermost and middle thirds of the shaft (51). These levels are considered together as the results are similar. The incidence of non-union was 38 per cent. There was no significant difference in non-union between the 22 patients who received operative treatment and the 29 patients who were conservatively treated but the death rate was twice as high in the conservative group ( 67 per cent). Union was achieved in 66 per cent of those treated with an intramedullary nail. Fractures of the lowermost third of the shaft and of the supracondylar region (11). The incidence of non-union in these regions was 55.6 per cent. The numbers were small but it should be noted that all six instances of non-union were in the group of seven patients who received internal fixation. At this level of the femur the death rate was higher in the operated group (64 per cent).

\section{Timing of internal fixation}

The relationship between the timing of internal fixation and non-union was examined. "Early" as defined by Smith (1964) means within six days of fracture. In the subtrochanteric group no significant difference in the incidence of non-union was found between the fractures treated by early internal fixation and those where treatment was delayed. However, in the 29 fractures of the shaft that were internally fixed, only four per cent of those treated early suffered non-union compared with 87.5 per cent of those where treatment was delayed. The high incidence of non-union in the delayed group is significant $(P<0.01)$.

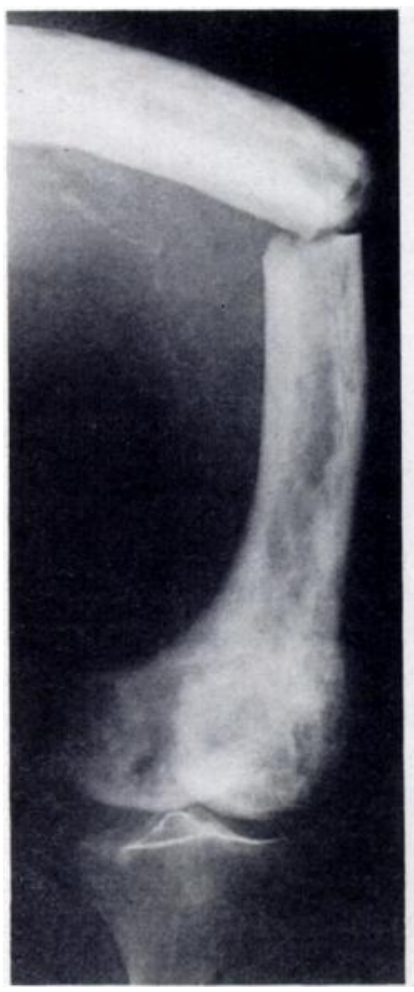

Fig. 1

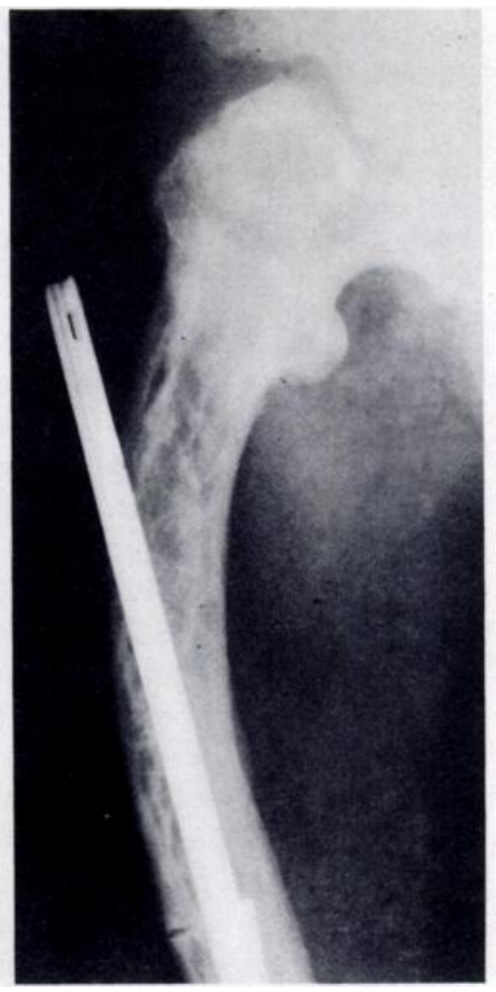

Fig. 2

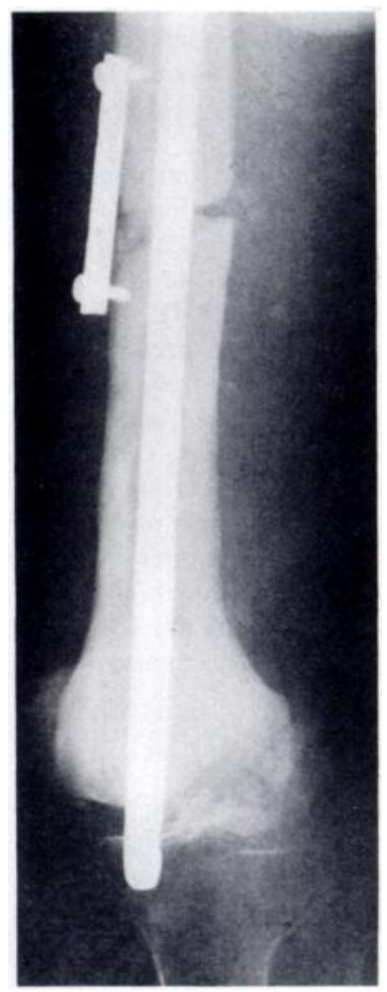

Fig. 3

The problem of soft bone. The nail has penetrated the shaft proximally and the knee distally. The antirotation plate is loose 10 days after operation. 


\section{Complications at operation}

In 49 per cent of surgical cases there were significant difficulties at operation. The commonest problem was soft bone ( 25 per cent) resulting in poor fixation (Figs 1 to 3). Troublesome bleeding occurred in 11 per cent but the deficit was easily met by transfusion; in one case, the patient exsanguinated as the result of pulsatile bleeding from bone. Deformity occurred in 10 per cent and dense bone was found in three per cent.

\section{DISCUSSION}

Non-union. The most striking feature of this study is the overall incidence of non-union of 40 per cent, much higher than the highest previously reported figure of 25 per cent (Grundy 1970). Eleven of Grundy's 16 cases of non-union were in the femoral neck. If the problem fractures of the subtrochanteric region and the uppermost and middle thirds of the shaft are considered, the incidence of non-union in this study ( 36.4 per cent) is nearly three times as high as the highest figure previously reported (Barry 1969). It is unlikely that this difference is accounted for by the relatively small regional variations in the incidence of Paget's disease (Barker et al. 1977).

Certain factors may have led to the mistaken concept of healing in these fractures. A short follow-up and radiographs of poor penetration undoubtedly led to a false sense of security in some studies; the average follow-up in this study was three years four months. Cases recorded as refracture at the same site were probably examples of non-union. Several observers noticed that callus was abundant in these fractures but callus is not a reliable sign of union in Paget's disease. It was Jaffe (1933) who first noted that in Paget's disease the callus itself was often involved in the disease process. In Figures 4 and 5 the displacement of the fracture allows an unobstructed view of the callus which can be seen to have the same coarse trabeculation as the diseased shaft. Thus in Paget's disease the only reliable signs of union are lack of mobility at the fracture site, lack of pain on weight-bearing and radiological evidence of trabeculae crossing the disappearing fracture line.

Complications. The commonest difficulty at operation was soft bone. It is not often appreciated, however, that dense bone, although uncommon, can present a major technical problem in Paget's disease. This is illustrated in Figure 6 which also demonstrates the typical appearance of non-union with coarse, tenuous callus and a fracture line still clearly visible two years after the fracture.

\section{Treatment}

Femoral neck fractures. Grundy (1970) reported 100 per cent non-union in fractures at this level and stated that "the cumulative experience leads to the conclusion that in Paget's disease the difficulties of internal fixation or prosthetic replacement at this site are best avoided".

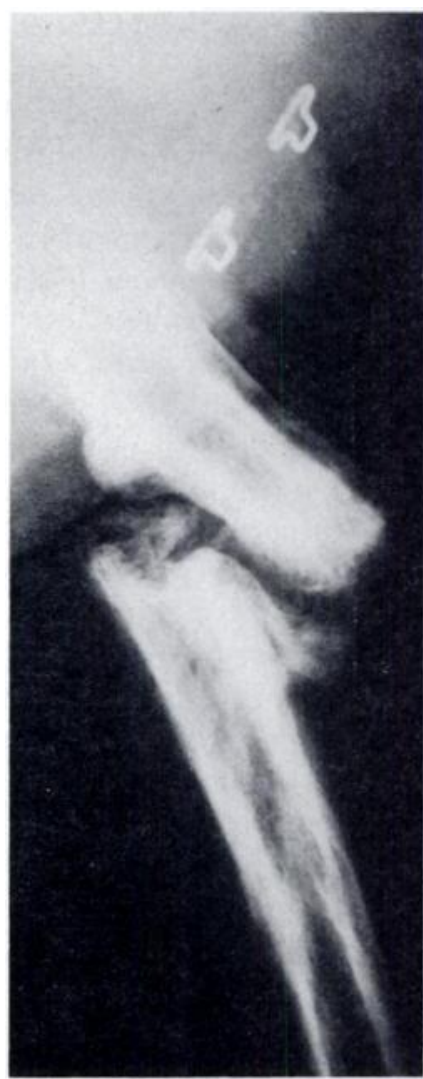

Fig. 4

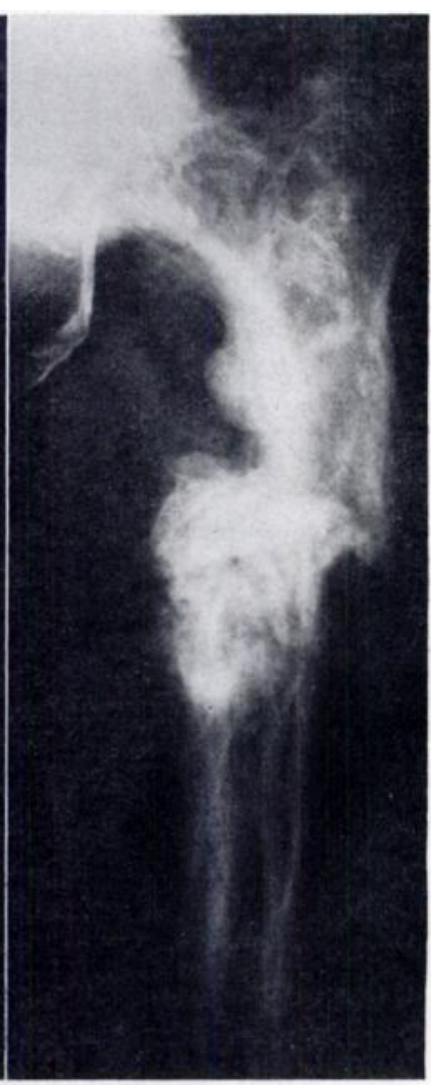

Fig. 5

The callus may itself be involved in the disease process (see text).

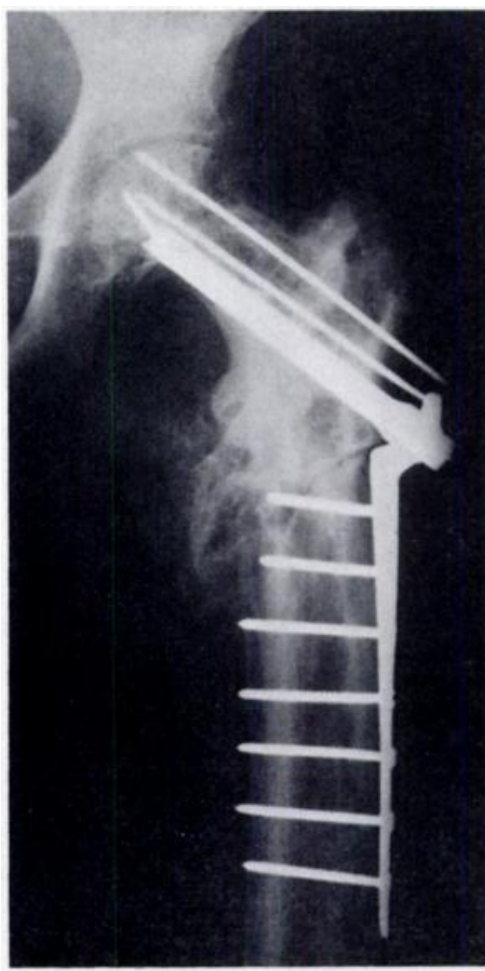

Fig. 6

The problem of dense bone. In attempt ing to drive the nail through the dense bone of the femoral neck when fixing the subtrochanteric fracture, a high subcapital fracture was incurred. Both fractures resulted in non-union. 
He recommended early mobilisation with the acceptance of inevitable non-union but not necessarily pain. In this study 75 per cent had a painful non-union, but seven of the nine patients with a femoral head replacement were able to walk without pain, and protrusio acetabuli was not a problem. Thus prosthetic replacement is recommended since the previous pessimism regarding this treatment seems unjustified.

Trochanteric fractures. A high death rate occurred in the conservatively treated group and all the cases of non-union were those where a one-piece nail-plate had been used, which may be because it cannot conform to the deformity as easily as the two-piece assembly (Fig. 7). A two-piece pin and plate is therefore recommended.

Subtrochanteric fractures. Conservative treatment gave difficulty in controlling the position of the fracture and the resulting high incidence of varus deformity carries an increased risk of refracture; this treatment was also associated with a high death rate. As this fracture occurs at the point of maximal bowing of the femur it provides considerable technical problems with the insertion of an intramedullary nail. A two-piece pin and plate is therefore recommended and it can be easily applied.

Fractures of the uppermost and middle thirds of the shaft. There was a high death rate after conservative treatment and the incidence of non-union increased with delay in surgical treatment. Therefore intramedullary nailing within six days of fracture is recommended and,

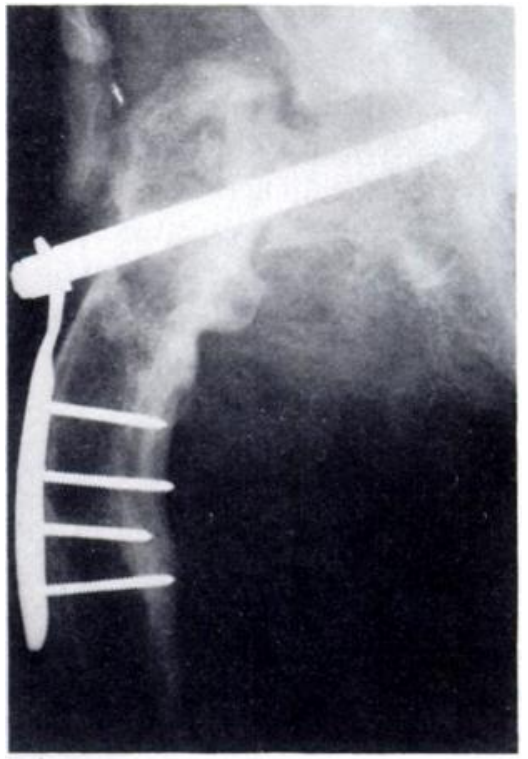

Fig. 7

How a two-piece apparatus may be adapted to the deformity. The nail has crossed the hip joint.

although there were technical problems, two thirds of the fractures so treated united.

Fractures of the lowermost third of the shaft and of the supracondylar region. All the instances of non-union were in the operated group, and the death rate was higher. A conservative approach is therefore recommended at this level.

I would like to thank the Department of Medical Statistics of the West Midlands Regional Health Authority for their help in tracing the hospital records, and the orthopaedic surgeons of the West Midlands for allowing me to review their patients. I am grateful to Mr N. R. Gill and the Medical Photographic Department of the Birmingham Accident Hospital for providing the illustrations, to Miss E. Edwards for providing the references and to Dr W. S. Munro and the Armour Pharmaceutical Company for practical assistance in the preparation of this paper. It is a pleasure to acknowledge my debt to Mr J. R. Pearson and especially to Mr M. H. M. Harrison for much helpful criticism of the text.

\section{REFERENCES}

Ackerman LV, Spjut HJ, Abell MR et al. Bones and Joints. Internal Academy of Pathology Monographs of Pathology No 17. Baltimore: Williams \& Wilkins Company, 1976:151.

Adams JC. Outline of fractures. 7th ed. Edinburgh and London: Churchill Livingstone, 1978:291

Apley AG. System of orthopaedics and fractures. Sth ed. London: Butterworths, 1977:76.

Barker DJP, Clongh PWL, Guyer PB, Gardner MJ. Paget's disease of bone in 14 British towns. Br Med J 1977;1:1181-3.

Barnes R, Brown JT, Garden RS, Nicoll EA. Subcapital fractures of the femur. J Bone Joint Surg [Br] 1976;58-B:2-24.

Barry HC. Fractures. In: Paget's disease of bone. Edinburgh and London: E \& S Livingstone Ltd, 1969:105-35.

Berruex P. Traitement par plaque des fractures et deformations axiales des membres dans la maladie de Paget. Rev Chir Orthop 1978;64:123-9.

Beyer U, Paul D. Frakturen bei Ostitis deformans Paget. Zentralbl Chir 1972;97:470-6.

BUvoet OLM, Jansen AP. Thyrocalcitonin in Paget's disease. Lancet 1967;2:471-2.

Blanco O, Stivel M, Mautalen C, Schajowicz F. Familial idiopathic hyperphosphatasia. J Bone Joint Surg [Br] 1977;59-B:421-7.

Boxus B. Le traitement chirurgical des complications ostéoarticularies de la maladie de Paget. Acta Orthop Belg 1974;40:471-80.

Bralloford JF. Paget's disease of bone: its frequency and complications. Br J Radiol 1938;11:507-32.

Daniluk A, Witwickd T. Deformations of the skeleton and pathological fractures in Paget's disease. Chir Narzadow Ruchu Ortop Pol 1975;40:637-42. (in Polish).

de Mourgues G, Comtet J-J, Placher L. Les fractures dans la maladie osseuse de Paget. Rev Chir Orthop 1967;53:657-66.

DePalma AF. The management of fractures and dislocations. 2 vols. 2nd ed. Philadelphia: WB Saunders Company, 1970;1:25.

de Seze S, Lascerre Ch, Mazabraud H. Fracture a grand déplacement d'un fémur pagétique. Rev Rhum Mal Ostéoartic 1956;23:599-601.

Deves M. ed. Geriatric orthopaedics. London: Academic Press, 1977:163-4.

Dickson DD, Camp JD, Ghormley RK. Osteitis deformans: Paget's disease of bone. Radiology 1945;44:449-70.

Driesen APPM, Magerl F. Fractures in Paget's disease of bone. Arch Chir Neerl 1976;28:101-13.

Grundy M. Fractures of the femur in Paget's disease of bone. J Bone Joint Surg [Br] 1970;52-B:252-63.

Hubbard MJS. The treatment of femoral shaft fractures in the elderly. J Bone Joint Surg [Br] 1974;56-B:96-101. 
Jacobs P. Osteolytic Paget's disease. Clin Radiol 1974;25:137-44.

Jaffe HL. Paget's disease of bone. Arch Pathol 1933;15:83-131.

Lake ME. Studies of Paget's disease (osteitis deformans). J Bone Joint Surg [Br] 1951;33-B:323-35.

Lake ME. The pathology of fracture in Paget's disease. Aust NZ J Surg 1958;27:307-12.

Lasserre Ch. Les fractures au cours de la maladie de Paget. Rev Rhum Mal Ostéoartic 1956;23:229-305.

Lemaire R. Les fractures des os longs dans la maladie de Paget. Acta Orthop Belg 1974;40:481-98.

London PS. A Practical Guide to the Care of the Injured. Edinburgh and London: E \& S Livingstone Ltd, 1967:722.

Louyot P, Pourel J, Delagontte JP, Zanett A. Quelques aspects inhabituels de fractures d'os pagetique. Rev Rhum Mal Ostéoartic 1975;42:653-60.

MacLeod J. ed. Davidson's principles and practice of medicine. 11th ed. Edinburgh and London: Churchill Livingstone, $1974: 791$.

Marchi B, Cittadini G. Le fratture istantanee in osso pagetico. Minerva Ortop 1968;19:615-29.

Murphy FG. Osteitis deformans, "Paget's disease", with fracture of the femur and prompt union. J Bone Joint Surg 1934;16:981-5.

Murray RO, Jacobson HG. The radiology of skeletal disorders. Exercises in diagnosis. 2nd ed. Edinburgh and London: Churchill Livingstone, $1977 ; 2: 881$.

Newman FW. Paget's disease: a statistical study of eighty-two cases. J Bone Joint Surg 1946;28:798-804.

Nicholas JA, Killoran P. Fracture of the femur in patients with Paget's disease. J Bone Joint Surg [Am] 1965;47-A:450-61.

Paget Sir J. On a form of chronic inflammation of bones (osteitis deformans). Trans $R$ Medicochir Soc Lon 1877;60:37-63.

Paterson CR. Metabolic disorders of bone. Oxford: Blackwell Scientific Publications, 1974:244.

Rains AJH, Ritchie HD, eds. Bailey and Love's short practice of surgery. 17th ed. London: H. K. Lewis \& Company Ltd. 1977:286-7.

Rauis A. Etude statistique sur la maladie de Paget. Acta Orthop Belg 1974;40:499-530.

Redden J, Hooking DJ, Vennart W. Fissure fractures in Paget's disease. J Bone Joint Surg [Br] 1977;59-B:251.

Rockwood CA Jr, Green DP. Fractures. Philadelphia: J. B. Lippincott Company, 1975;1:256.

Rogers MH, Ulin R. Fractures in Paget's disease. J Bone Joint Surg 1936;18:914-20.

Scott RB. Price's textbook of the practice of medicine. 11 th ed. London: Oxford University Press, 1973:962.

Simon G. Principles of bone X-ray diagnosis. 3rd ed. London: Butterworths, 1973:179.

Smith JEM. The results of early and delayed internal fixation of fractures of the shaft of the femur.J Bone Joint Surg [Br] 1964;46-B:28-31.

Tavernier L, Lasserre Ch. Les fractures dans la maladie de Paget. Rev Chir Orthop 3rd series 1937;24:569-77.

Traver CA. The association of fractures and Paget's disease (osteitis deformans). NY State J Med 1936;36:242-6.

Turek SL. Orthopaedics: principles and their application. 3rd ed. Philadelphia: JB Lippincott Company, 1977:653.

Wiles P, Sweetnam R. Essentials of orthopaedics. 4th ed. London: J \& A Churchill, 1965:518.

Wilson JN. Watson-Jones Fractures and joint injuries. 5th ed. Edinburgh and London: Churchill Livingstone, 1976;2:1275.

Woytek G. Ostitis deformans Paget und Frakturdisposition. Monatsschr Unfallheilkd 1932;39:560-70.

Zickel RE. An intramedullary fixation device for the proximal part of the femur. J Bone Joint Surg [Am] 1976;58-A:866-72. 